\title{
A general method of analyzing the correlation between sustainability and curriculum of higher education in China
}

\author{
Chunhua Feng \\ School of Mechanical Engineering, University of Shanghai for Science and Technology, Shanghai \\ 200093, China
}

Keywords: sustainable development; systematic method; sustainability analysis; higher education; curriculum

\begin{abstract}
With the increasing awareness of sustainable development in higher education institutions, it has become an essential part for setting training program and curriculum. The key step is how to integrate sustainable development requirements into professional courses among college students education to make the theoretical groundwork possible in all disciplines. The purpose of this paper is to present a systematic approach through top-bottom to integrate sustainability contents into curriculum as well as quantifying influence degree of different courses on sustainable development. It mainly takes the training program setting of higher education institutions as the research object, and analyzes the relevance of training goals, graduation requirements, core courses, curriculum system and sustainability factors. Taking general education courses, subject basic courses, professional courses and optional courses as examples, the relevance between sustainable factors and curriculum design is quantified combining qualitative and quantitative analysis method for providing valuable reference for decision makers. All majors of University of Shanghai for Science and Technology (USST) are analyzed through considering whether or not containing sustainability factors like environment, society and economy. The data are collected from the training program of all majors in USST. Furthermore, the major of mechanical design, manufacturing and automation in USST is used as a case study to reveal the importance of integrated sustainable factors, and the significance of higher education of engineering specialty for the implementation of sustainable development.
\end{abstract}

\section{Introduction}

In recent decades, sustainable development (SD) has been widely recognized in various industries, such as manufacturing (Chiarini, 2014), design (Shapira et al., 2017), packaging (Nigel et al., 2017), chemicals (Rajeev et al., 2019), etc. The goal of SD is to achieve the harmonious development of environment, economy and society during technology progress (Kwatra et al., 2020). Higher education institutions generally refer to colleges and universities and scientific research institutes that provide teaching and research conditions as well as authorize the awarding of degrees. Colleges and universities are the main front for promoting ecological civilization, whose teachers and students are 
the disseminators and main forces of ecological civilization construction. Thus, higher education will develop in the direction of diversified structures, basically realizing the modernization of education, and basically becoming a powerful country in higher education. In the current education system, economy is an education goal that has always existed in most disciplines. With the continuous improvement of environmental awareness, the degree of attention to environmental load continues to increase, and social factors are concerned. Higher education as institution of cultivating talents plays a very important role in promoting sustainable development idea into teaching and students education procedure (Zhou et al., 2020). Therefore, the concept of higher education for sustainable development has been recognized as a priority, which make the students better understand sustainability (Wu and Shen, 2016). The main contents of sustainable design teaching include: sustainable development (resources, social responsibility, systems and services, designer responsibility, business driving force), design oriented towards sustainability (guiding students in what aspects should be embedded with sustainability factors). Although higher education institutions could provide strong support for the realization of sustainable development goals (Colin and Remmer, 2020), how to effectively implement sustainable factors under the current education model has not been well addressed. The aim of this paper is to research how to formulate training goals and set the related courses using qualitative and quantitative methods.

The integration of SD into higher education is an important initiative for the construction of ecological civilization. At the undergraduate and graduate level, integrating sustainability factors in curriculum and teaching process will be critical for achieving sustainable design and manufacturing in their work activities. As a result, more and more university leaders and faculty have begun to recognize the importance of sustainability. Furthermore, many higher education institutions around the world have put more and more sustainability attention for improving market competitiveness of college graduates in future work. For instances, Nikolic et al., (2020) research the students' attitudes towards SD in Serbia finding that they have recognized the main determinants and support the sustainability knowledge increasing. Argento et al., (2020) analyze the sustainability integration through different disciplines cooperate to reveal how sustainability is integrated into the courses. Nomura and Abe (2010) review the education development direction and the guiding role of government in the field of sustainable development in Japan. Niu et al. (2010) analyze the developments, challenges, and prospects of higher education for SD in China as initial survey, finding some problems such as the limited resources and capacity, reposition the course, and syllabus changes. Chhokar (2010) reviews the India's education policy in the field of SD, which concentrate on curriculum innovation. Another aspect of research focus on the integration situation assessment of higher education for SD. For example, Yuan and Zuo (2013) survey the 1134 students from all divisions of the Shandong University to assess its development for SD. The investigation result could provide a useful reference when deepen develop SD. Finnveden et al. (2020) evaluate 47 higher education institutions in Sweden through writing self-evaluation report. The current research about higher education with SD focus on the following points: perception of students regarding sustainability (Rampasso et al., 2019); implementation strategies of SD for students and professionals (Eyto et al., 2008; Ramísio et al., 2019); paradigms setting in engineering practice and education for sustainable development (Halbe et al., 2015); complex evaluation of sustainability in education (Staniškis and Katiliūte, 2016); policy integration for sustainable development implementation (Vargas et al., 2019).

On the other hand, the condition of simply training skills can no longer meet the needs of society, and hence, it is necessary to pay attention to environmental and social aspects of education in addition to master the necessary professional and technical to cultivate talents (Kapitulčinová et al., 2018). Therefore, sustainable thinking should be one part of core curriculum in higher education through integrating into other types of professional courses. For integrating sustainability into a series of 
courses in the existing engineering education, there are mainly two things: how to make plan in the implementation of the system; how to effectively in the teaching practice of embedding sustainability (Leal Filho et al., 2019). The formulation and implementation of the training program will play a decisive role in the impact of future talents on work. Therefore, it is necessary to integrate sustainable factors into the training programs and training goals of higher education institutions, and to improve targeted training programs for different disciplines and professional requirements in order to better implement strategic measures for sustainable development. Objectives, graduation requirements, curriculum settings, and curriculum syllabus are integrated with sustainability factors. The trained professionals can truly understand and master the concrete implementation of sustainable measures, so as to achieve timely handling conflict issues of the gap between sustainability and professional technology. Take engineering education as an example, engineering occupies a very important position in higher education institutions because of its importance in promoting social development (Thürer et al., 2018). Traditional engineering education designs optimized programs from an economic point of view, and the current negative effects of these programs on social and environmental factors should also be considered as well as engineering responsibility (Rampasso et al., 2018). In other words, engineers should take sustainable development as the goal of professional promotion (Lilley and Lofthouse, 2009). Therefore, it is imperative to improve the engineering curriculum system. The curriculum is the inevitable requirement of universities to comply with the development of the market era, so as to better serve the future development of students. Through the above analysis, it can be seen that qualitative analysis method is adopted in most research, while being lack of systematic method with quantitative method.

The training plan is the overall design and implementation plan of professional talent training, and is the main basis for organizing the education and teaching process and carrying out teaching outcomes (Filho et al., 2019). Students must choose and study prescribed courses in accordance with the requirements of a certain major in the training plan, and only those who reach the rated credits of the training plan can graduate. The goal of talent training and its value orientation reflect the purpose and direction of university education, and are the objective embodiment and specific requirements of the university's mission. Previous studies on sustainable development of higher education mainly focused on students' attitudes towards sustainability, teachers' perceptions of sustainability, and the evaluation of sustainable development by educational institutions. The main research of this article is how colleges and universities integrate sustainable development in the process of formulating training programs. And taking the University of Shanghai for Science and Technology as a case study, it analyzed the development of the school's training programs for all majors, the curriculum settings of different training objectives, and conducted a quantitative analysis for sustainability-related courses.

The other sections of this article is arranged as follows. The quantitative analysis of the relationship between cultivation scheme and sustainable development is given in Section 2. The development of training goals in University of Shanghai for Science and Technology (USST) is shown in Section 3. Last, the conclusions is shown in Section 4.

\section{Methodology}

This paper propose a systematic method for analyzing correlation of sustainable development and curriculum to assist the decision maker in higher education set training goal and plan. The contribution to teachers and students is better understanding the influence degree of different courses on SD. The content includes two points that are modelling the sustainable development requirements and mapping theirs into curriculum. 


\subsection{Modelling the sustainable development requirements for higher education}

The flowchart of integration of sustainability related factors with course programs is shown in Fig.1. Firstly, sustainability factors must be considered as training objectives and corresponding graduation requirements. Then, different level courses with detailed courses should be set under the condition of SD.

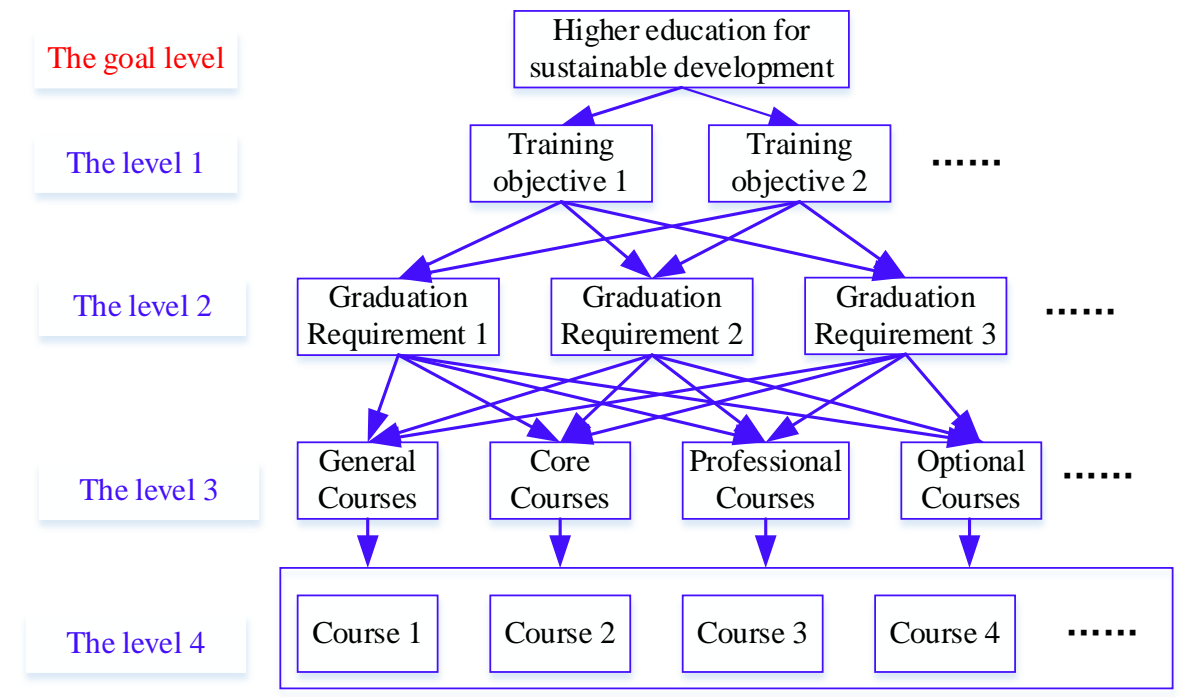

Fig. 1 The systematic approach with top-bottom integrating sustainability content

The goal level is to make decision to increase the sustainability contents in the higher education for sustainable development, which is decisive for the effective implementation of SD in university and colleges. When the sustainability consciousness increasing, the decision-makers will promote the implementation of SD in various disciplines of their department. The first level is to make the corresponding training programmer according to the detailed information of different disciplines.

Training objectives is the first core part in training program of higher education, and hence, it must consider sustainability contents as the top decision making task. For example, the traditional training objective on mechanical design, manufacture and automation major is that cultivate senior engineering and technical personnel engaged in mechanical product design, development, manufacturing and automated testing and control. If integrating sustainability factors, the training objectives are decomposed into five parts as follows:

(1) With the ability of put forward, analysis and solve the problem of complex engineering field using the knowledge of engineering mathematics and mechanical engineering.

(2) Be able to track advanced technologies in mechanical engineering and related fields, use modern tools innovatively to design, develop and produce related products, and have management capability for engineering project.

(3) Understand and abide by professional ethics, be familiar with engineering standardization, and consider the influence of legal, environmental and sustainable development factors comprehensively in engineering practice. This objective involves the sustainable development thinking.

(4) Be able to carry out multi-disciplinary and cross-cultural technical exchanges with the ability of teamwork, communication and expression.

(5) With an international perspective, demonstrated commitment and progress in lifelong learning and professional development.

The aim of training objectives for higher education talent is to meet a series of graduation requirements. When sustainability need is set as one of graduation requirements in second level, the college students and teachers will put some extent attention on it. The results will inevitably promote 
sustainable development consciousness. Then, the graduation requirements will be mapped into courses modules like general courses, core courses, professional courses and optional courses. In the last level, different courses are set in corresponding graduation requirements, which help teachers and students deeply understand how to achieve SD in courses.

\subsection{Mapping sustainable development requirements into curriculum}

Four aspects are discussed in the process of mapping sustainable development requirements into detailed curriculum as follows:

(1) The relationship between training objectives and sustainable development requirements

Each university has a different positioning, so it has a different target positioning for sustainable development. The expression of semantics directly reflects the future positioning of the sustainable development of universities. On the basis of traditional training goals, it is need to integrate or add sustainable development goals related to environmental, economic and social factors. In this mapping process, it is inevitable to determine the relationship between existing training goals and sustainable development. The triangular fuzzy number is used as the quantification method as shown in Table 1.

Table 1 The identification of influence degree

\begin{tabular}{ccc}
\hline The linguistic variables & Fuzzy number & Triangular fuzzy number \\
\hline Extremely little & $\tilde{1}$ & $(1,1,1)$ \\
Very little & $\tilde{2}$ & $(1,2,3)$ \\
Relatively little & $\tilde{3}$ & $(2,3,4)$ \\
little & $\tilde{4}$ & $(3,4,5)$ \\
fair & $\tilde{5}$ & $(4,5,6)$ \\
A little big & $\tilde{6}$ & $(5,6,7)$ \\
Relatively big & $\tilde{7}$ & $(6,7,8)$ \\
Very big & $\tilde{8}$ & $(7,8,9)$ \\
Extremely big & $\tilde{9}$ & $(8,9,10)$ \\
\hline
\end{tabular}

The relationship between training objectives and sustainable development requirements is expressed as

$$
\begin{aligned}
\mathrm{R}_{\mathrm{To}} & =\left[\begin{array}{lrrr} 
& \text { En } & \text { Ec } & \text { So } \\
\text { To1 } & \mathrm{X} & \mathrm{X} & \mathrm{X} \\
\mathrm{To} 2 & \mathrm{X} & \mathrm{X} & \mathrm{X} \\
\cdots & \cdots & \cdots & \cdots \\
\mathrm{Ton} & \mathrm{X} & \mathrm{X} & \mathrm{X}
\end{array}\right] \\
\mathrm{R}_{\mathrm{Gr}} & =\left[\begin{array}{llrr}
\mathrm{Gr} 1 & \mathrm{X} & \mathrm{Ec} & \mathrm{X} \\
\mathrm{Gr} 2 & \mathrm{X} & \mathrm{X} & \mathrm{X} \\
\cdots & \cdots & \cdots & \cdots \\
\mathrm{Grm} & \mathrm{X} & \mathrm{X} & \mathrm{X}
\end{array}\right]
\end{aligned}
$$

where $X$ is the triangular fuzzy number representing the relationship training objective and sustainable development as well as graduation requirements and sustainable development, and $\mathrm{X}=$ $\left[\mathrm{l}_{\mathrm{ij}}, \mathrm{m}_{\mathrm{ij}}, \mathrm{u}_{\mathrm{ij}}\right]$. The calculation rule for the addition of two triangular fuzzy numbers is $\mathrm{X}_{1}=\left[\mathrm{l}_{1}, \mathrm{~m}_{1}, \mathrm{u}_{1}\right]$ and $\mathrm{X}_{2}=\left[\mathrm{l}_{2}, \mathrm{~m}_{2}, \mathrm{u}_{2}\right]$ expressed as $\mathrm{X}_{1} \oplus \mathrm{X}_{2}=\left(\mathrm{l}_{1}+\mathrm{l}_{2}, \mathrm{~m}_{1}+\mathrm{m}_{2}, \mathrm{u}_{1}+\mathrm{u}_{2}\right)$. The total influence degree of the ith training objective for sustainable development is calculated as 


$$
\mathrm{IT}_{\mathrm{i}}=\sum_{\mathrm{j}=1}^{3} \tilde{\mathrm{x}}_{\mathrm{ij}}=\left(\sum_{\mathrm{j}=1}^{3} \mathrm{l}_{\mathrm{ij}}, \sum_{\mathrm{j}=1}^{3} \mathrm{~m}_{\mathrm{ij}}, \sum_{\mathrm{j}=1}^{3} \mathrm{u}_{\mathrm{ij}}\right), \quad \mathrm{i}=1,2, \cdots, \mathrm{n}
$$

Similarly, the total influence degree of the ith graduation requirements for sustainable development is calculated as

$$
\mathrm{IG}_{\mathrm{i}}=\sum_{\mathrm{j}=1}^{3} \tilde{\mathrm{x}}_{\mathrm{ij}}=\left(\sum_{\mathrm{j}=1}^{3} \mathrm{l}_{\mathrm{ij}}, \sum_{\mathrm{j}=1}^{3} \mathrm{~m}_{\mathrm{ij}}, \sum_{\mathrm{j}=1}^{3} \mathrm{u}_{\mathrm{ij}}\right), \quad \mathrm{i}=1,2, \cdots, \mathrm{m}
$$

Correspondingly, the weight of $i$ th training objective is calculated as

$$
\mathrm{W}_{\mathrm{i}}=\frac{\mathrm{IT}_{\mathrm{i}}}{\sum_{\mathrm{i}=1}^{\mathrm{n}} \mathrm{IT} \mathrm{T}_{\mathrm{i}}}
$$

According to the total influence value of different training objective and graduation requirements, the decision makers select the graduation requirements with bigger influence on sustainable development to set or improve the corresponding courses.

(2) The determination of influence degree of courses on SD

After graduation requirements identified, it could be as the basis for the curriculum, and set different weights for different courses. Different courses have different effects on sustainable development. Therefore, different courses are set up for graduation requirements related to sustainable development. For decision making process, decision makers could not be able to express their preference information accurately due to the factors of insufficient information, not quantitative indicators, and unavailable. In the people's cognitive practice, uncertainty and ambiguity is very common phenomenon when they design product. For example, when designer evaluates schemes, disagree and don't know describe two completely different information. However, uncertainty index is the most important feature of intuitionistic fuzzy sets. Hence, it is very appropriate to represent the uncertain information with intuitionistic fuzzy number. The influence degree of different course on SD is quantified as shown in Table 2.

Table 2 The influence degree of course on SD

\begin{tabular}{lc}
\hline \multicolumn{1}{c}{ Linguistic terms } & $\mathbf{1 / 9 - 9}$ scale \\
\hline Very small influence & $1 / 9$ \\
Small influence & $1 / 7$ \\
General influence & $1 / 5$ \\
Little big influence & $1 / 3$ \\
Medium influence & 1 \\
Relatively big influence & 3 \\
Big influence & 5 \\
Very big influence & 7 \\
Enormous big influence & 9 \\
\hline
\end{tabular}

In addition, the sustainability requirements affect the final design scheme selection in some extent for a given decision problem. Thus, the influence degree of each factor at every level by linguistic variables is described as Table 2, which is divided into nine grade. Saaty (1986) proposed 9 scaling technique, which expresses having extremely little influence using 1/9, while 9 represents extremely big influence. The degree of sustainability requirements contributing to the final design goal is described using intuitionistic fuzzy number. The advantage of intuitionistic fuzzy number is not only including membership degree and non-membership degree, but also considering the hesitant degree when expert making decision.

Suppose, $\mathrm{X}$ is a given nonempty set, then intuitionistic multiplicative set is

$$
\mathrm{D}=\left\{<\mathrm{x}, \rho_{\mathrm{D}}(\mathrm{x}), \sigma_{\mathrm{D}}(\mathrm{x})>\mid \mathrm{x} \in \mathrm{X}\right\}
$$

where $\rho_{D}(x)$ and $\sigma_{D}(x)$ represent respectively the membership degree and non-membership 
degree of element $x$ belonging to $A$ subset of $X$ in $X$. And meet the following condition:

$$
1 / 9 \leq \rho_{\mathrm{D}}(\mathrm{x}), \sigma_{\mathrm{D}}(\mathrm{x}) \leq 9, \rho_{\mathrm{D}}(\mathrm{x}) \sigma_{\mathrm{D}}(\mathrm{x}) \leq 1, \forall \mathrm{x} \in \mathrm{X}
$$

For simple calculation process, binary array $\left(\rho_{\mathrm{D}}(\mathrm{x}), \sigma_{\mathrm{D}}(\mathrm{x})\right)$ is called intuitionistic multiplicative number, and $D$ is the intuitionistic multiplicative number set.

(3) The weights determination of different courses on different graduation requirements

In order to make the proposed method clearer, the stepwise procedure is given below. As decision maker has different preference information for kinds of courses, thus judgment matrix of courses should be constructed. The preference degree of decision maker is determined according to the definition in Table 2.

The preference value is obtained by following steps:

Step 1: Defining the preference relations matrix

If there are $m$ courses $A=\left\{A_{1}, A_{1}, \cdots, A_{m}\right\}$, and the preference value for course $D P_{i}$ relative to $D P_{k}$ is $r_{i k}=\left(\rho_{i k}, \sigma_{i k}\right),(i, k=1,2, \ldots \ldots, m) . \rho_{\mathrm{ik}}$ expresses the degree of $D P_{i}$ superior to $D P_{k}$, while $\sigma_{\mathrm{ik}}$ expresses the degree of $D P_{i}$ is no better than $D P_{k}$. The constraint condition is $\rho_{\mathrm{ik}}, \sigma_{\mathrm{ik}} \in[0,1]$, $\rho_{\mathrm{ik}}+\sigma_{\mathrm{ik}} \leq 1, \rho_{\mathrm{ik}}=\sigma_{\mathrm{ik}}, \rho_{\mathrm{ii}}=\sigma_{\mathrm{ii}}=0.5(\mathrm{i}, \mathrm{k}=1,2, \cdots, \mathrm{m})$. Then, the decision maker's preference relations matrix is described as:

$$
R=\left(\begin{array}{cccc}
r_{11} & r_{12} & \cdots & r_{1 m} \\
r_{21} & r_{22} & \cdots & r_{2 m} \\
\cdots & \cdots & \cdots & \cdots \\
r_{m 1} & r_{m 2} & \cdots & r_{m m}
\end{array}\right)
$$

where $r_{i k}$ is the preference relations value of two courses.

Suppose $\mathrm{R}=\left(\mathrm{r}_{\mathrm{ik}}\right)_{\mathrm{m} \times \mathrm{m}}$ is the intuitionistic multiplicative preference relation, and $\mathrm{r}_{\mathrm{ik}}=$ $\left(\rho_{\mathrm{ik}}, \sigma_{\mathrm{ik}}\right)(i, k=1,2, \ldots \ldots, m)$.

Step 2: The calculation of intuitionistic multiplicative number

The preference matrix need to be estimated whether or not have consistency. Jiang et al. (2015) pointed that if there are two multiplicative preference relations as $C=\left(c_{i k}\right)_{m \times m}$ and $D=$ $\left(\mathrm{d}_{\mathrm{ik}}\right)_{\mathrm{m} \times \mathrm{m}}$, which satisfy the following relation:

$$
c_{i k}=\left\{\begin{array}{ll}
\rho_{i k}, & i<k \\
1, & i=k, \\
1 / \sigma_{i k}, & i>k
\end{array} \quad d_{i k}= \begin{cases}\sigma_{i k}, & i<k \\
1, & i=k \\
1 / \rho_{i k}, & i>k\end{cases}\right.
$$

And $\mathrm{c}_{\mathrm{ik}}=\mathrm{c}_{\mathrm{it}} \mathrm{c}_{\mathrm{tk}}, \mathrm{d}_{\mathrm{ik}}=\mathrm{d}_{\mathrm{it}} \mathrm{d}_{\mathrm{tk}}$, then we call $R$ with consistency.

Then calculate the CI and CR of multiplicative preference relations C and D based on AHP algorithm (Taha and Rostam, 2012) using Eq. (3).

$$
\mathrm{CI}=\frac{\lambda_{\max }-\mathrm{m}}{\mathrm{m}-1}, \mathrm{CR}=\frac{\mathrm{CI}}{\mathrm{RI}}
$$

where $\lambda_{\max }$ is the largest eigenvalue of multiplicative preference relations, while the value of RI is determined by multiplicity of multiplicative preference relations, (See Table 3).

Table 3 The value of RI

\begin{tabular}{llllllllll}
\hline Multiplicity & 2 & 3 & 4 & 5 & 6 & 7 & 8 & 9 & 10 \\
\hline RI & 0.00 & 0.58 & 0.90 & 1.12 & 1.24 & 1.32 & 1.41 & 1.45 & 1.49 \\
\hline
\end{tabular}

AHP method gave the consistency index CI and the consistency ratio CR to measure the level of 
inconsistency (Saaty, 1986). Similarly, judge matrix of intuitionistic multiplicative preference relation should also test the consistency due to its important role on following calculation. If there is $\mathrm{CR} \leq 0.1$ for both $\mathrm{C}$ and $\mathrm{D}$, then intuitionistic multiplicative preference relation has consistency. However, if either of the $\mathrm{C}$ and $\mathrm{D}$ meet $\mathrm{CR}>0.1$, then using row geometric mean method obtain the weight of inconsistency multiplicative preference relation as

$$
\tau_{i}=\frac{\left(\prod_{\mathrm{k}=1}^{\mathrm{m}} \mathrm{c}_{\mathrm{ik}}\right)^{\frac{1}{\mathrm{~m}}}}{\sum_{\mathrm{i}=1}^{\mathrm{m}}\left(\prod_{\mathrm{k}=1}^{\mathrm{m}} \mathrm{c}_{\mathrm{ik}}\right)^{\frac{1}{\mathrm{~m}}}}
$$

Based on the consistency definition of multiplicative preference relations, we can get the corresponding perfect consistency multiplicative preference relations $\bar{C}=\left(\bar{c}_{i k}\right)_{m \times m},\left(\bar{c}_{i k}=\tau_{i} / \tau_{k}\right)$ for inconsistency multiplicative preference relation $\mathrm{C}=\left(\mathrm{c}_{\mathrm{ik}}\right)_{\mathrm{m} \times \mathrm{m}}$. Similarly, it can get perfect consistency multiplicative preference relations $\bar{D}=\left(\bar{d}_{i k}\right)_{m \times m}$. Thus, it can construct a perfect consistency intuition multiplicative preference relations $\bar{R}=\left(\bar{\alpha}_{i k}\right)_{m \times m}$.

After that, it calculates the distance between corresponding elements in

$$
\mathrm{d}_{\mathrm{ik}}=\left|\lg \rho_{\mathrm{ik}}-\lg \bar{\rho}_{\mathrm{ik}}\right|+\left|\lg \sigma_{\mathrm{ik}}-\lg \bar{\sigma}_{\mathrm{ik}}\right|
$$

Finding the best value and corresponding elements $\left(\rho_{i k^{*}}, \sigma_{i k^{*}}\right)$ and $\left(\bar{\rho}_{i k^{*}}, \bar{\sigma}_{i k^{*}}\right)$ in $d_{i k}(i=$ $1, \cdots, \mathrm{m}-1 ; \mathrm{k}=\mathrm{i}+1, \cdots, \mathrm{m})$. Then let $\rho_{\mathrm{ik}^{*}}^{(\mathrm{p})}=\rho_{\mathrm{ik}^{*}}, \sigma_{\mathrm{ik}^{*}}^{(\mathrm{p})}=\sigma_{\mathrm{ik}^{*}}$, and $p=1$. where $p$ is the iterations. After that, we get the corrected intuitionistic multiplicative number using Eq.(10) until the consistency meet requirement.

$$
\rho_{\mathrm{ik}^{*}}^{(\mathrm{p}+1)}=\sqrt{\rho_{\mathrm{ik}^{*}}^{(\mathrm{p})} * \bar{\rho}_{\mathrm{ik}^{*}}}, \sigma_{\mathrm{ik}^{*}}^{(\mathrm{p}+1)}=\sqrt{\sigma_{\mathrm{ik}^{*}}^{(\mathrm{p})} * \bar{\sigma}_{\mathrm{ik}^{*}}}
$$

Step 3: The weight of each factor based on intuitionistic multiplicative preference relation

Let the priority weights set is $\omega=\left(\omega_{1}, \omega_{2}, \cdots, \omega_{n}\right)^{(T)}$, which is deduced through $G=\left(\alpha_{j q}\right)_{n \times n}$. Thus, $\omega_{j} / \omega_{q}$ must be able to respond the value size of $\alpha_{j q}=\left(\rho_{j q}, \sigma_{j q}\right)$, where $\rho_{j q}$ and $\sigma_{j q}$ respect the degree of $C_{j}$ priority and not priority $C_{q}$. When $\rho_{j q} \cdot \sigma_{j q} \leq 1$, the degree of $C_{j}$ priority $C_{q}$ least is $\rho_{j>}$, most is $1 / \sigma_{j>}$, expressed as $\left[\rho_{j>}, 1 / \sigma_{j>}\right]$.

$$
\alpha_{j>}=\prod_{q=1}^{n} \alpha_{j q}=\left[\prod_{q=1}^{n} \rho_{j q}, \prod_{q=1}^{n} 1 / \sigma_{j q}\right], j=1,2, \cdots, n
$$

where vector $\alpha_{j>}=\left(\alpha_{1>}, \alpha_{2 \succ}, \cdots, \alpha_{n>}\right)^{T}$ represent the degree of target $C_{j}$ priority other schemes. Let $\left[\omega_{j}^{\prime}, \bar{\omega}_{j}\right](j=1,2, \cdots, n)$ is a list of interval number which is equivalent to $\alpha_{j>}(j=1,2, \cdots, n)$. Based on probability formula, we get

$$
p\left(\omega_{j} \geq \omega_{q}\right)=\max \left(1-\max \left(\frac{\bar{\omega}_{q}-\omega_{j}^{\prime}}{\bar{\omega}_{j}-\omega_{j}^{\prime}+\bar{\omega}_{q}-\omega_{q}^{\prime}}, 0\right), 0\right)
$$

If $p_{j q}=\mathrm{p}\left(\omega_{j} \geq \omega_{q}\right)$, then construct probability matrix $P=\left(p_{j q}\right)_{n \times n}$, in which $p_{j q} \geq 0, p_{j q}+$ $p_{q j}=1$ and $p_{j j}=0.5$. Then priority weights of matrix $P$ are calculated as

$$
\omega_{j}=\frac{1}{n(n-1)}\left(\sum_{q=1}^{n} p_{j q}+\frac{n}{2}-1\right)
$$

Therefore, we can get priority weights vector $\omega=\left(\omega_{1}, \omega_{2}, \cdots, \omega_{n}\right)^{(T)}$ of intuitionistic multiplicative preference relation. The calculation process from Eqs. (6) to (13) is for one intuitionistic multiplicative matrix, other preference value with corresponding matrix could be obtained using similar procedure.

(4) The influence degree of courses on SD 
The final influence degree of courses on SD is also determined by the weights of training objectives and graduation requirements, which is expressed as

$$
\mathrm{FD}_{\mathrm{ij}}=\mathrm{w}_{\mathrm{gri}} \cdot \mathrm{w}_{\mathrm{dj}}
$$

where $F D_{i j}$ is the value of $i$ th graduation requirement with $j$ th course, $w_{g r i}$ is the weight of $i$ th graduation requirement, while $w_{d j}$ is the weight of $j$ th course.

\section{A Chinese University study-USST}

The case study of this paper is the engineering major of Shanghai University for Science and Technology, and mainly focuses on the mechanical design, manufacturing and automation major. USST has many distinctive features with a history of over 110 years. As a key university included in the "Double First-class Initiative" of Shanghai, it is co-sponsored by the State Administration of Science, Technology and Industry for National Defense and the Municipal Government of Shanghai. Focusing on engineering, the school has seen a balanced development of other such disciplines as engineering, science, economics, management, literature, law and arts, making it an applicationresearch oriented university under the key construction of Shanghai City. Currently, USST has more than 24 thousand students, among which 17,000 are undergraduates and 7, 500 are post-graduate students. There are 15 schools, 2 departments of education, 56 undergraduate programs, 8 first-level disciplines authorized to offer doctoral degrees, 4 post-doctoral research stations, 27 first-level disciplines authorized to offer master degrees and 11 professional master degrees.

This paper aims to analyze the professional related to sustainability and accounted for cultivating professional and settings of Shanghai University of science and technology project. There are total of 12 colleges in this university, including seven subjects that are economics, literature, science, engineering, medicine, management, art involving 58 majors. Subject distribution is shown in Fig.2.

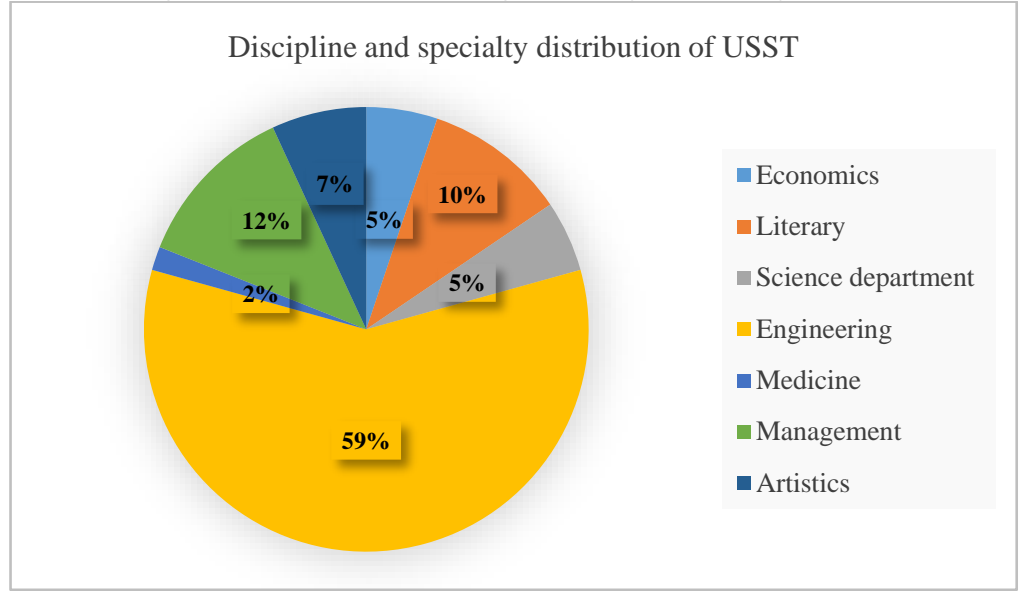

Fig.2 Subject distribution of USST

In most of the engineering majors of USST in 2019, the graduation requirements basically include the factors of sustainable development. At least 2 to 5 points are the graduation requirements of sustainable factors, indicating that factors related to SD are taken into account in the setting of training programs in higher education. The training program from 2014 to 2020 is analyzed. In the graduation requirements, sustainability related factors are not included in 2014 and 2015, but they are gradually increased after 2016. The timeline of the change of the culture target is shown in Fig. 3. 


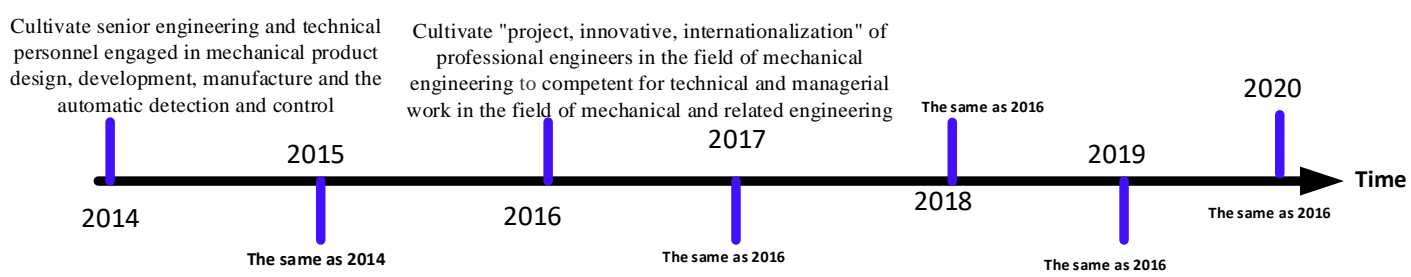

Fig.3 The timeline of change of culture objectives

The aim of 2014 and 2015 is to cultivate senior engineering and technical personnel engaged in mechanical product design, development, manufacture and the automatic detection and control. After 2015, the aim has changed into "project, innovative, internationalization" of professional engineers in the field of mechanical engineering to competent for technical and managerial work in the field of mechanical and related engineering. There are 5 training objectives are determined as shown in Table 4 after 2016 for major of mechanical design and manufacturing and automation in USST.

Table 4 The training objectives contents

\begin{tabular}{ll}
\hline Training objectives & Contents \\
\hline To1 & With the ability of put forward, analysis and solve the problem of \\
& complex engineering field using the knowledge of engineering \\
& mathematics and mechanical engineering. \\
To2 & Be able to track advanced technologies in mechanical engineering \\
& and related fields, use modern tools innovatively to design, \\
& develop and produce related products, and have management \\
& capability for engineering project. \\
& Understand and abide by professional ethics, be familiar with \\
engineering standardization, and consider the influence of legal, & factors \\
To3 & comprenensively in engineering practice. This objective involves \\
& the sustainable development thinking. \\
& $\begin{array}{l}\text { Be able to carry out multi-disciplinary and cross-cultural } \\
\text { technical exchanges with the ability of teamwork, communication } \\
\text { To4 }\end{array}$ \\
& $\begin{array}{l}\text { With an international perspective, demonstrated commitment and } \\
\text { progress in lifelong learning and professional development. }\end{array}$ \\
\hline
\end{tabular}

According to the contents of each training objective, the relationship between each training objective and sustainable development could be quantified as

$$
\mathrm{R}_{\mathrm{To}}=\left[\begin{array}{cccc} 
& \text { En } & \text { Ec } & \text { So } \\
\text { To1 } & \tilde{1} & \tilde{1} & \tilde{1} \\
\text { To2 } & \tilde{3} & \tilde{4} & \tilde{2} \\
\text { To3 } & \tilde{9} & \tilde{7} & \tilde{9} \\
\text { To4 } & \tilde{1} & \tilde{1} & \tilde{1} \\
\text { To5 } & \tilde{1} & \tilde{1} & \tilde{1}
\end{array}\right], \quad \mathrm{IT}_{\mathrm{o}}=\left[\begin{array}{cc}
\mathrm{SD} \\
\text { To1 } & \tilde{3} \\
\text { To2 } & \tilde{9} \\
\text { To3 } & \tilde{25} \\
\text { To4 } & \tilde{3} \\
\text { To5 } & \tilde{3}
\end{array}\right]
$$

From the value of $R_{T o}$, it could be seen that To3 has the maximum correlation with sustainable development, while other training objectives have some extent relationship. In order to better achieve the training goals, the graduation requirements of this major include the goals of sustainable design and manufacturing, sustainable development. After 2016, the graduation requirements are divided into 12 points as shown in Table 5. 
Table 5 The graduation requirements in USST

\begin{tabular}{|c|c|}
\hline $\begin{array}{l}\text { Graduation } \\
\text { requirements }\end{array}$ & Contents \\
\hline Gr1 & $\begin{array}{l}\text { Engineering knowledge: Able to use mathematics, natural science engineering } \\
\text { foundation and professional knowledge to solve complex mechanical } \\
\text { problems. }\end{array}$ \\
\hline Gr2 & $\begin{array}{l}\text { Problem analysis: Able to apply the basic principles of mathematics, natural } \\
\text { sciences and engineering sciences, identify expressions and analyze complex } \\
\text { mechanical engineering problems through literature research to obtain } \\
\text { effective conclusions. }\end{array}$ \\
\hline Gr3 & $\begin{array}{l}\text { Design/development solutions: with the ability of developing solution for } \\
\text { complex engineering problem in the mechanical field, designing process flow } \\
\text { to meet the specific needs of the mechanical and electrical system, parts, and } \\
\text { be able to reflect innovation consciousness in the design process, considering } \\
\text { social, health, safety, legal, cultural and environmental factors }\end{array}$ \\
\hline Gr4 & $\begin{array}{l}\text { Research: Ability to study complex engineering problems in the mechanical } \\
\text { field based on scientific principles and using scientific methods, including } \\
\text { designing experiments, analyzing and interpreting data, and obtaining } \\
\text { reasonable and effective conclusions through information synthesis. }\end{array}$ \\
\hline Gr5 & $\begin{array}{l}\text { Use modern tools: able to develop, select and use appropriate technology, } \\
\text { resources, modern engineering tools and information technology tools for } \\
\text { complex engineering problems in the mechanical field, predict and simulate } \\
\text { mechanical design, manufacturing and control processes, and understand their } \\
\text { limitations. }\end{array}$ \\
\hline Gr6 & $\begin{array}{l}\text { Engineering and society: Could take reasonable analysis based on related } \\
\text { background knowledge of mechanical engineering, evaluate influences of } \\
\text { mechanical product design, manufacturing process and product use on the } \\
\text { society, health, safety, legal and cultural, and take reasonable measures to } \\
\text { reduce or avoid its adverse effects. }\end{array}$ \\
\hline Gr7 & $\begin{array}{l}\text { Environment and sustainable development: ability to understand and evaluate } \\
\text { the influence in the field of manufacturing process and product use to the } \\
\text { environment, of the social sustainable development for mechanical complex } \\
\text { engineering problems. }\end{array}$ \\
\hline Gr8 & $\begin{array}{l}\text { Professional standards: with the sense of humanities and social science } \\
\text { literacy, social responsibility, could understand and abide by engineering } \\
\text { professional ethics and norms in the mechanical product design, } \\
\text { manufacturing, fulfill the responsibility. }\end{array}$ \\
\hline Gr9 & $\begin{array}{l}\text { Individuals and teams: able to assume the roles of individuals, team members, } \\
\text { and leaders in a multidisciplinary team. }\end{array}$ \\
\hline Gr10 & $\begin{array}{l}\text { Communication: Ability to effectively communicate and communicate with } \\
\text { industry colleagues and the public on complex engineering issues in the } \\
\text { mechanical field, including writing reports and design manuscripts, making } \\
\text { statements, expressing clearly or responding to instructions. And have a } \\
\text { certain international perspective, able to communicate and exchange in a } \\
\text { cross-cultural context. }\end{array}$ \\
\hline Gr11 & $\begin{array}{l}\text { Project management: understand and grasp the principle of project } \\
\text { management and economic decision method, and can be applied in a } \\
\text { multidisciplinary environment }\end{array}$ \\
\hline Gr12 & $\begin{array}{l}\text { Lifelong learning: Have the consciousness of independent learning and } \\
\text { lifelong learning, and have the ability to continuously learn and adapt to } \\
\text { professional development. }\end{array}$ \\
\hline
\end{tabular}


The correlation graduation requirements and sustainable development is quantified as

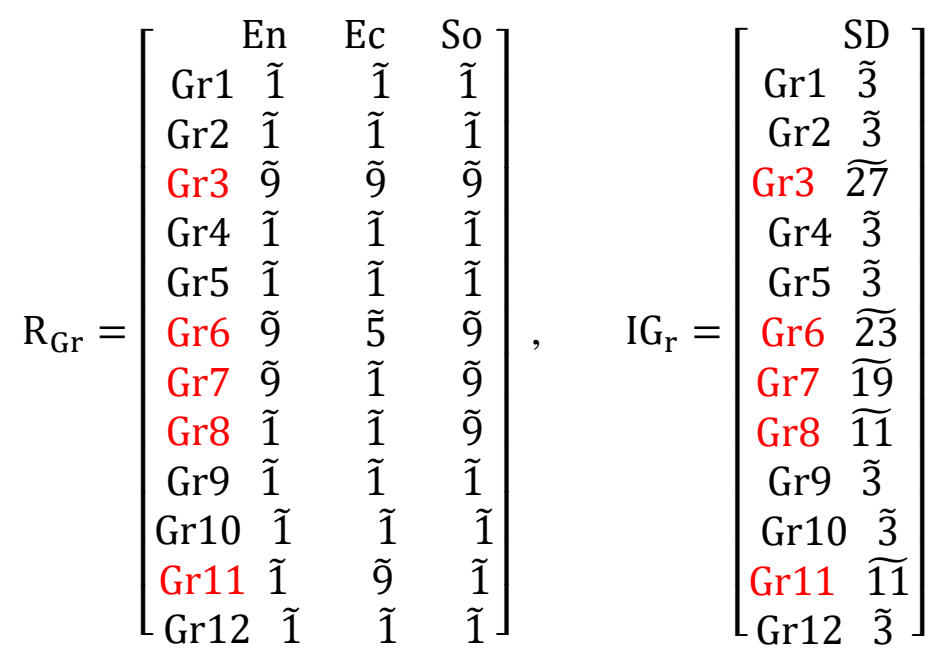

From the value of $\mathrm{IG}_{\mathrm{r}}$, it can be seen that $\mathrm{Gr}_{3}, \mathrm{Gr}_{6}, \mathrm{Gr}_{7}, \mathrm{Gr}_{8}$ and $\mathrm{Gr}_{11}$ have the bigger correlation with sustainable development. The weights could be calculated using calculation rule of triangular fuzzy number as

$$
\mathrm{w}_{\mathrm{gr}}=\left(\mathrm{w}_{\mathrm{gr} 3}, \mathrm{w}_{\mathrm{gr} 6}, \mathrm{w}_{\mathrm{gr} 7}, \mathrm{w}_{\mathrm{gr} 8}, \mathrm{w}_{\mathrm{gr} 11}\right)=(0.3,0.25,0.21,0.12,0.12)
$$

The indicators related to sustainability included in the graduation requirements from 2014 to 2020 are shown in Table 6.

Table 6 Graduation requirements related to sustainability factors

\begin{tabular}{llllll}
\hline Year & GR3 & GR 6 & GR 7 & GR 8 & GR 11 \\
\hline 2014 & $\times$ & $\times$ & $\times$ & $\times$ & $\times$ \\
2015 & $\times$ & $\times$ & $\times$ & $\times$ & $\times$ \\
2016 & $\checkmark$ & $\checkmark$ & $\checkmark$ & $\checkmark$ & $\checkmark$ \\
2017 & $\checkmark$ & $\checkmark$ & $\checkmark$ & $\checkmark$ & $\checkmark$ \\
2018 & $\checkmark$ & $\checkmark$ & $\checkmark$ & $\checkmark$ & $\checkmark$ \\
2019 & $\checkmark$ & $\checkmark$ & $\checkmark$ & $\checkmark$ & $\checkmark$ \\
2020 & $\checkmark$ & $\checkmark$ & $\checkmark$ & $\checkmark$ & $\checkmark$ \\
\hline
\end{tabular}

Each graduation requirements related to the sustainable are supported by related courses, while different classes have different weights representing the support strength. This paper analyzes the five indicators related to sustainable and support programs as shown in Table 7 . The preference degree matrix for the three courses of Gr3 is expressed as

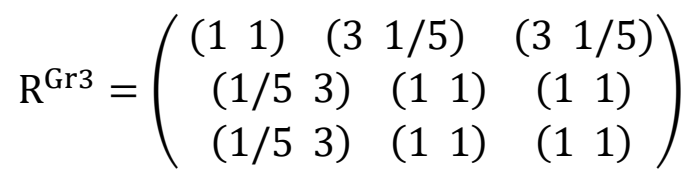

Using the Eqs. (6)-(14), the weight of graduation requirements Gr3 is $(0.5,0.25,0.25)$. Similarly, the weights of all related to sustainable development courses could be obtained (see Table 7). The core courses include: engineering drawing, theoretical mechanics, material mechanics, mechanical principles, mechanical design, mechanical equipment structure design, mechanical testing and control foundation, mechanical manufacturing technology, numerical control technology, comprehensive design of complex electromechanical systems. 
Table 7 GR Index allocation and course configuration

\begin{tabular}{|c|c|c|c|c|}
\hline GR & Weight & Index allocation & Course configuration & Weight \\
\hline \multirow[b]{3}{*}{ Gr3 } & \multirow[b]{3}{*}{0.3} & \multirow{3}{*}{$\begin{array}{l}\text { Be able to analyze and } \\
\text { demonstrate the feasibility of the } \\
\text { solution through technical and } \\
\text { economic evaluation under the } \\
\text { constraints of safety, } \\
\text { environment, and law. }\end{array}$} & Mechanical equipment structure design & 0.5 \\
\hline & & & Engineer thinking training & 0.25 \\
\hline & & & Mechanical Design & 0.25 \\
\hline \multirow{5}{*}{ Gr6 } & \multirow{5}{*}{0.25} & \multirow{5}{*}{$\begin{array}{l}\text { Be able to evaluate the social } \\
\text { impact of the project from } \\
\text { multiple angles, and take } \\
\text { reasonable measures to reduce or } \\
\text { avoid its adverse impact. }\end{array}$} & Mechanical structure understanding experiment & 0.25 \\
\hline & & & Graduation Project & 0.3 \\
\hline & & & Enterprise Management Foundation & 0.15 \\
\hline & & & Quality Control & 0.15 \\
\hline & & & Production planning and control & 0.15 \\
\hline \multirow{8}{*}{ Gr7 } & \multirow{5}{*}{0.105} & \multirow{5}{*}{$\begin{array}{l}\text { Understand the meaning and } \\
\text { connotation of environmental } \\
\text { protection and sustainable social } \\
\text { development. }\end{array}$} & Advanced Manufacturing Technology & 0.15 \\
\hline & & & Intelligent manufacturing technology & 0.15 \\
\hline & & & Precision machining technology & 0.15 \\
\hline & & & Innovative thinking and entrepreneurial practice & 0.275 \\
\hline & & & Introduction to Engineering & 0.275 \\
\hline & \multirow[b]{3}{*}{0.105} & \multirow{3}{*}{$\begin{array}{l}\text { Be able to correctly understand } \\
\text { and evaluate the impact of the } \\
\text { manufacture and use of } \\
\text { mechanical products on the } \\
\text { environment and sustainable } \\
\text { development of society. }\end{array}$} & Graduation Project & 0.5 \\
\hline & & & Mechanical equipment structure design & 0.25 \\
\hline & & & Thermal Engineering Foundation & 0.25 \\
\hline \multirow{9}{*}{ Gr8 } & \multirow{4}{*}{0.06} & \multirow{4}{*}{$\begin{array}{l}\text { Understand mechanical } \\
\text { engineers and related } \\
\text { professional standards, and have } \\
\text { a sense of social responsibility. }\end{array}$} & Engineer thinking training & 0.2917 \\
\hline & & & Science and Engineering Ethics & 0.375 \\
\hline & & & Production Practice & \\
\hline & & & $\begin{array}{l}\text { Mechanical Engineering Comprehensive } \\
\text { Practice/Experiment }\end{array}$ & 0.1667 \\
\hline & \multirow{5}{*}{0.06} & \multirow{5}{*}{$\begin{array}{l}\text { Be able to comply with } \\
\text { professional ethics and } \\
\text { regulations in the design, } \\
\text { manufacture and application of } \\
\text { mechanical products, and have } \\
\text { legal awareness. }\end{array}$} & Science and Engineering Ethics & 0.3 \\
\hline & & & Advanced Manufacturing Technology & 0.15 \\
\hline & & & Intelligent manufacturing technology & 0.15 \\
\hline & & & Precision machining technology & 0.15 \\
\hline & & & Ideological and Political & 0.25 \\
\hline \multirow{4}{*}{ Gr11 } & \multirow[t]{2}{*}{0.06} & \multirow{2}{*}{$\begin{array}{l}\text { Understand the basic methods of } \\
\text { mechanical engineering project } \\
\text { management, be able to conduct } \\
\text { economic analysis, and make } \\
\text { reasonable decisions. }\end{array}$} & $\begin{array}{l}\text { Enterprise Management Foundation } \\
\text { Quality Control } \\
\text { Production planning and control } \\
\end{array}$ & $\begin{array}{l}0.2083 \\
0.2083 \\
0.2083 \\
\end{array}$ \\
\hline & & & Graduation Project & 0.375 \\
\hline & \multirow[b]{2}{*}{0.06} & \multirow{2}{*}{$\begin{array}{l}\text { Grasp the basic principles of } \\
\text { production organization and } \\
\text { management of machinery } \\
\text { manufacturing enterprises, and } \\
\text { conduct effective analysis and } \\
\text { evaluation of their technical } \\
\text { economy. }\end{array}$} & $\begin{array}{l}\text { Production Practice } \\
\text { Mechanical Engineering } \\
\text { Practice/Experiment }\end{array}$ & $\begin{array}{l}0.2 \\
0.2\end{array}$ \\
\hline & & & $\begin{array}{l}\text { Enterprise Management Foundation } \\
\text { Quality Control } \\
\text { Production planning and control }\end{array}$ & $\begin{array}{l}0.2 \\
0.2 \\
0.2\end{array}$ \\
\hline
\end{tabular}

From the Fig.2, it can be seen that Engineering takes account for 59\% in USST. Thus it is the key discipline when integrate sustainability factors into higher education process. While other disciplines are less or temporary consider sustainability factors in training plan formulation. In 34 professional engineering disciplines, the sustainable related professional graduation requirements have 27 (See Fig.4), which take $79.4 \%$ of engineering disciplines and $46.5 \%$ of all major proportion in whole school. In order to better understand and grasp the relationship sustainability factors and training plan in the future talent professional ability, quantitative analysis method should be adopt for guiding 
specific training scheme. It will help to improve and the writing of the syllabus in the quantitative method.

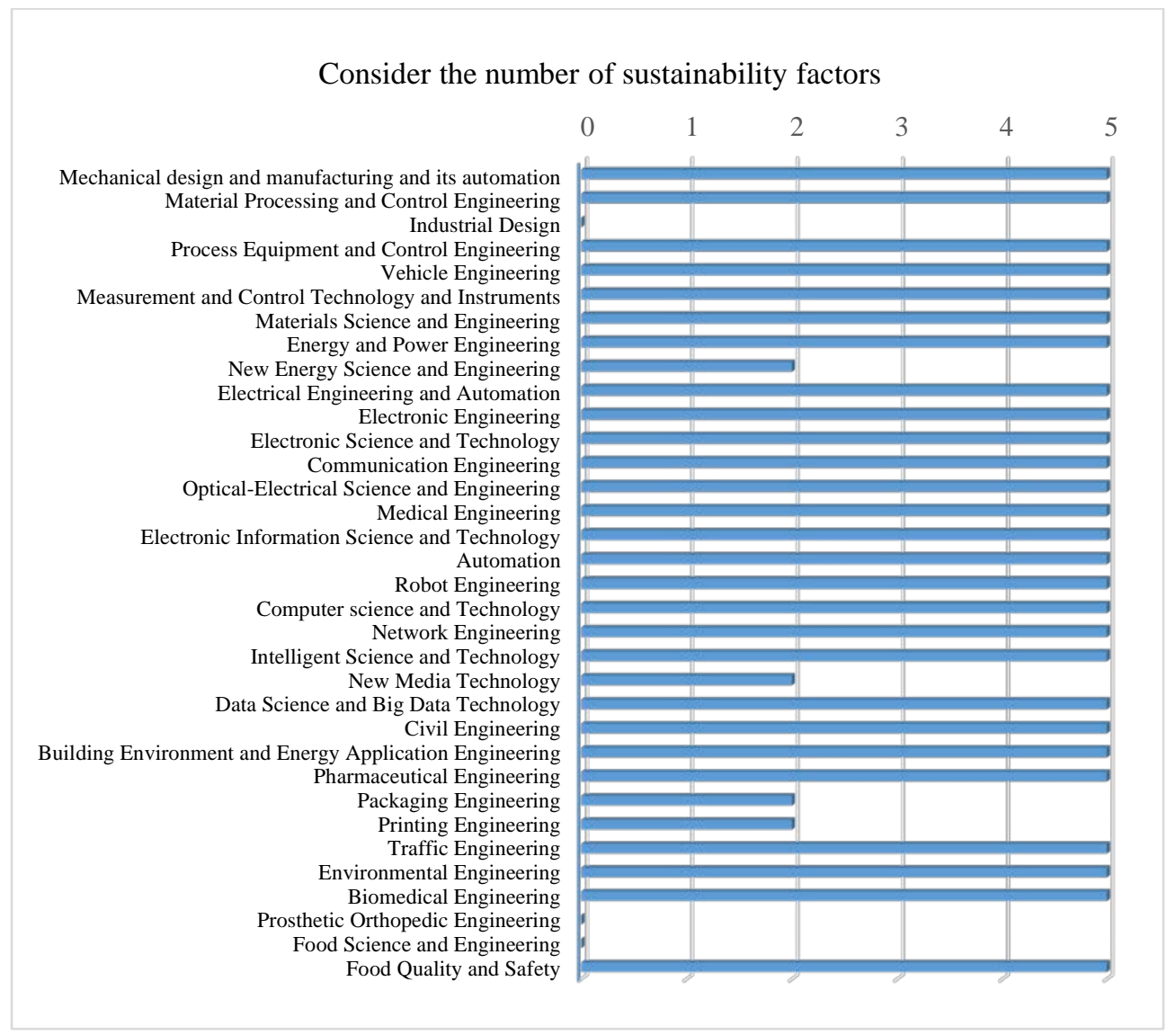

Fig.4 The major considering sustainability factors

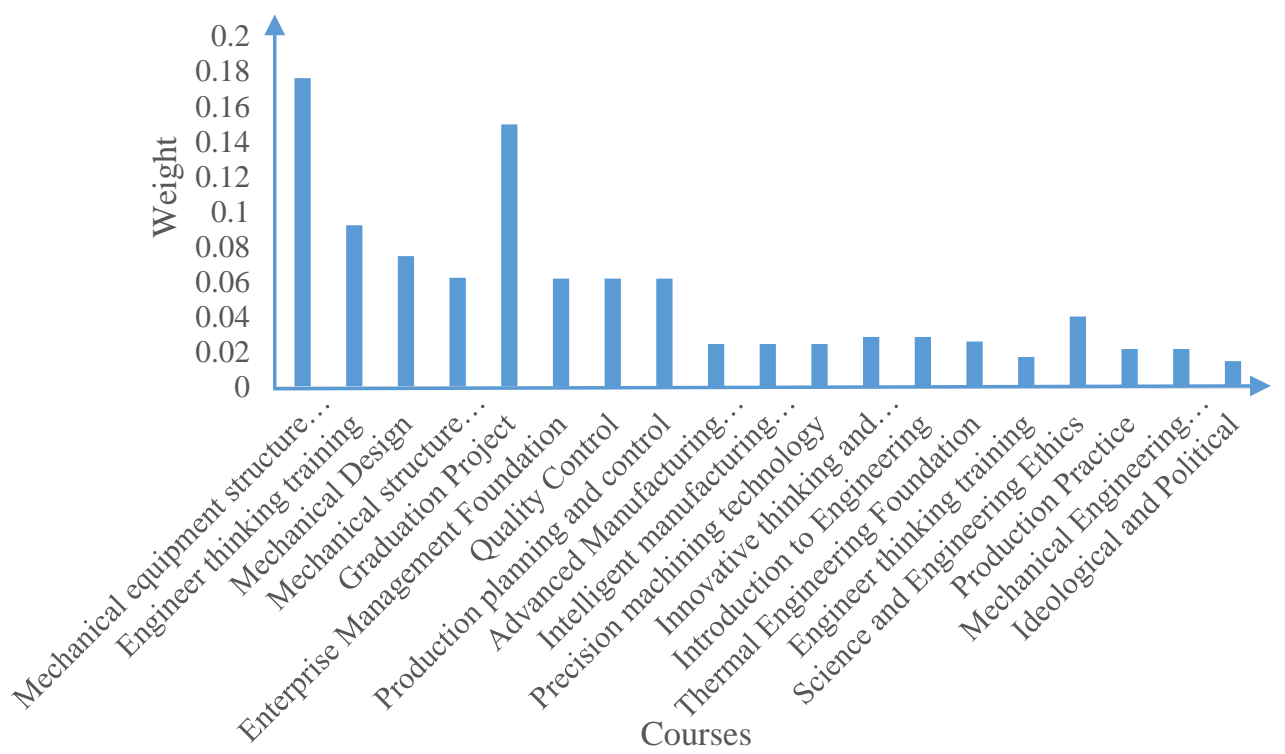

Fig.5 The influence degree of each curriculum on SD

Based on the mechanical design and manufacturing and its automation for the specific object of study, training plan formulation in a total of 12 graduation requirements, which involves the sustainability factors or with related with five to $41.7 \%$ of all graduation requirements. Each 
graduation requirements can be resolved to index point, different indicators point corresponding to the related courses, the weight of different courses of related, on the basis of this process, sustainability factors analysis, so that they can understand and sustainability factors correlation degree of quantitative indicators, and targeted to the related contents in the course of further improvement.

The larger the value, the greater the influence, and the weight has been assigned, as shown in Table 7. The integrating weight of each course has been obtained using Eq. (15) as shown in Fig.5.

It can be seen from Fig. 5 that in terms of the degree of impact of the curriculum on sustainability, the mechanical equipment structure design curriculum has the greatest impact. The ranking of influence degree is the mechanical equipment structure design, graduation project, engineer thinking training, mechanical design and so on. Because it determines more than $80 \%$ of the product life cycle performance during the design phase. Secondly, the graduation design as a link to comprehensively assess the knowledge structure of students, it is of great significance to the application of knowledge and the integration of sustainability factors. In addition, engineer thinking training and mechanical design courses also have an important influence on sustainability factors. Based on this, sustainability factors can be integrated in an orderly manner in the outline writing and teaching process of the above courses. According to the influence degree of courses on SD, the improvement suggestions could be given as follows:

(1) Mechanical equipment structure design: The basic principles and methods of mechanical equipment structural design are elaborated in this curriculum. The main contents include the introduction of the connotation, general requirements and basic process of mechanical equipment structural design, as well as the requirements of typical machining processes (cutting, casting, welding and plastic forming) on the structural design of parts. Then, it takes the machine tool structure as an example to introduce in detail the design requirements and design principles of the main system and structure of the machine tool. Finally, it introduces the optimization design method of mechanical equipment structure.

From the contents of this curriculum, it can be seen that the use of comprehensive knowledge is its main feature for helping students understand how to improve the mechanical equipment structure. Because the design stage has an important impact on the sustainability of the entire life cycle of the product, this course has the greatest impact on sustainable development education. Therefore, factors related to sustainable design and manufacturing are added to the teaching content when writing the course syllabus.

(2) Graduation Project: Graduation design is the task of a comprehensive project design after students have completed all courses. It involves comprehensive project planning of design, manufacturing, mechanics, electronics and other multi-disciplinary subjects, and can comprehensively examine the ability of students to master corresponding knowledge. Many steps such as selection of design scheme, machining process and parameters should be decided in the whole process. Therefore, integrating sustainability-related factors in this process can enable students to truly appreciate how to make the plan or product meet the basic functions and integrate sustainability factors, ultimately making the product more in line with the needs of sustainable development. Students could have real experience through considering the design scheme in the context of sustainability to deepen understanding its connotation.

(3) Engineer thinking training: It is of great significance to the formation of engineer thinking mode. The thinking mode can not only promote the journey of innovative consciousness, but also enhance the understanding of sustainable development concepts and the absorption of knowledge points.

(4) Mechanical Design: It is a basic technical course to train students to have the ability of mechanical design, which is a compulsory main course in the teaching plan of mechanical majors. "Mechanical Design" comprehensively uses the basic theory, engineering technology and production 
practice knowledge of prerequisite courses such as mechanical drawing, basic mechanical manufacturing, metal materials and heat treatment, tolerance and technical measurement, theoretical mechanics, material mechanics, mechanical principle and computer application foundation, etc. It could solve problems such as the working principle, material selection, design method, structural design and engineering application of general parts and components in the machine. Through the teaching of each link of this course, students will receive systematic training on the basic theories, design methods and design skills of mechanical parts and component design, and then master the design rules and technical measures of mechanical design. Furthermore, students have the ability to design general mechanical transmission devices or simple machinery as well as learn about professional courses and engage in mechanical technology work in the future. Therefore, this course also plays an important role in the teaching plan of mechanical majors when consider the sustainable development requirements.

In addition to the four courses mentioned above that have a greater impact on sustainable development, other courses also have a certain impact. According to actual needs, the integration of corresponding sustainability factors will play an important role in cultivating talents in future disciplines of higher education institutions.

\section{Conclusions and future work}

The setting of training objectives of higher education institutions determines the quality of talent training, and hence, this paper analysis how to integrate SD into training setting and courses. In order to better understand the influence degree of courses, quantitative method is used to help course outline development and instruct teachers and students to implement sustainable development. In process of courses schedule for specific professional, the different weights should be determined according to the influence degree on SD. The contribution of this paper mainly is the proposed systematic method not only help decision makers to select or improve the training objectives and graduation requirements, but also analysis the influence degree of different courses on SD combining qualitative and quantitative methods. It solves the problem of being lack of detailed design process of higher education for sustainable development. Using the proposed method, the decision makers could integrate the topic of sustainable development in the new or existing curriculum as well as find out the influence degree on SD.

The all majors of USST are investigated in training schedule, graduation requirements, and courses distribution on the basis of SD needs. The survey results show that the USST considered sustainable development in most of the majors of engineering in the formulation of the training program after 2016, but did not consider in the science, literature and other disciplines. Taking mechanical design and manufacturing and its automation as an example, the graduation requirements have been broken down and different courses have been set, where some courses support multiple graduation requirements at the same time. According to the support courses for different graduation requirements, the teachers could increase more contents about SD and guide students to improve the consciousness in specific design and manufacturing process and continuous learning in future. Each higher education institute should add the SD into their training schedule and give the detailed information related to courses and research. Furthermore, the existing syllabus should be updated enhancing new perspectives from SD goals.

There are also some limits about this research, which focus on training schedule and courses without students' learning outcomes. In future, we will continue track the learning results about the SD with professional techniques, which need more time to track it. Moreover, the useful feedback loops for the understand degree of students on SD will also be established using quantitative approach during the examination process and graduation project. 


\section{Declaration of interests}

The authors declare that they have no known competing financial interests or personal relationships that could have appeared to influence the work reported in this paper.

\section{Acknowledgments}

This research is funded by the National Natural Science Foundation of China Grant No. 51605294.

\section{References}

[1] Argento, D., Einarson, D., Mrtensson, L., Persson, C., Westergren, A., 2020. Integrating sustainability in higher education: a Swedish case. International Journal of Sustainability in Higher Education, 21(6), 1131-1149.

[2] Chhokar, K.B., 2010. Higher education and curriculum innovation for sustainable development in India. International Journal of Sustainability in Higher Education, 11(2), 141-152.

[3] Chiarini, A., 2014. Sustainable manufacturing-greening processes using specific Lean Production tools: an empirical observation from European motorcycle component manufacturers. Journal of Cleaner Production. 85, 226-233.

[4] Colin B., Remmer S., 2020. Sensemaking of a sustainability transition by higher education institution leaders. Journal of Cleaner Production 256, 120299.

[5] Eyto, A., Mahon, M., Hadfield, M., Hutchings, M., 2008. Strategies for developing sustainable design practice for students and SME professionals. European Journal of Engineering Education, 33(3), 331-342.

[6] Filho, W.L., Skanavis, C., Kounani, A., Brandli, L.L., et al., 2019. The role of planning in implementing sustainable development in a higher education context. Journal of Cleaner Production, 235, 678-687.

[7] Finnveden, G., Friman, E., Mogren, A., Palmer, H., Linn Svärd., 2020. Evaluation of integration of sustainable development in higher education in Sweden. International Journal of Sustainability in Higher Education, 21(4), 685-698. [8] Halbe, J., Adamowski, J., Pahl-Wostl, C., 2015. The role of paradigms in engineering practice and education for sustainable development. Journal of Cleaner Production, 106, 272-282.

[9] Jiang, Y., Xu, Z., Yu, X., 2015. Group decision making based on incomplete intuitionistic multiplicative preference relations. Information Sciences, 2015, 295:33-52.

[10] Leal Filho, W., Skouloudis, A., Brandli, L.L., Salvia, A.L., Avila, L.V., Rayman-Bacchus, L., 2019. Sustainability and procurement practices in higher education institutions: barriers and drivers. Journal of Cleaner Production, 231, 12671280.

[11] Lilley, D., Lofthouse, V., 2009. Sustainable design education - considering design for behavioural change. Engineering Education, 4(1), 29-41.

[12] Kapitulčinová, D., AtKisson, A., Perdue, J., Will, M., 2018. Towards integrated sustainability in higher education e Mapping the use of the Accelerator toolset in all dimensions of university practice. Journal of Cleaner Production, 172, 4367-4382.

[13] Kwatra, S., Kumar, A., Sharma, P., 2020. A critical review of studies related to construction and computation of Sustainable Development Indices. Ecological Indicators, 112, 106061.

[14] Nigel, D.S., Herpen, E.V., Lans, I. A.V.D., Ligthart, T.N., Trijp, H. C.M.V., 2017. Consumer response to packaging design: the role of packaging materials and graphics in sustainability perceptions and product evaluations. Journal of Cleaner Production, 162, 286-298.

[15] Nikolic, V., Vukic, T., Maletaski, T., Andevski, M., 2020. Students' attitudes towards sustainable development in serbia. International Journal of Sustainability in Higher Education, 21(4), 733-755.

[16] Niu, D., Jiang, D., Li, F., 2010. Higher education for sustainable development in China. International Journal of Sustainability in Higher Education, 11(2), 153-162.

[17] Nomura, K., Abe, O., 2010. Higher education for sustainable development in japan: policy and progress. International Journal of Sustainability in Higher Education, 11(2), 120-129.

[18] Rajeev, A., Rupesh, K.P., Sidhartha, S.P., 2019. Sustainable supply chain management in the chemical industry: Evolution, opportunities, and challenges. Resources, Conservation \& Recycling, 149, 275-291.

[19] Ramísio, P.J., Costa Pinto, L.M., Gouveia, N., Costa, H., Arezes, D., 2019. Sustainability Strategy in Higher Education Institutions: Lessons learned from a nine-year case study. Journal of Cleaner Production, 222, $300-309$.

[20] Rampasso, I.S., Anholon, R., Silva, D., et al., 2018. An analysis of the difficulties associated to sustainability insertion in engineering education: Examples from HEIs in Brazil. Journal of Cleaner Production, 193, 363-371.

Rampasso, I.S., Anholon, R., Silva, D., Cooper Ordoñez, R.E., Santa-Eulalia, L.A., et al., 2019. Analysis of the perception of engineering students regarding sustainability. Journal of Cleaner Production, 233, 461-467.

[21] Saaty, T. L., 1986. Axiomatic Foundation of the Analytic Hierarchy Process. Management Science. 32(7), 841-855. 
[22] Shapira, H., Ketchie, A., Nehe, M., 2017. The integration of design thinking and strategic sustainable development. Journal of Cleaner Production, 140, 277-287.

[23] Staniškis, J.K., Katiliūte, E., 2016. Complex evaluation of sustainability in engineering education: case \& analysis. Journal of Cleaner Production, 120, 13-20.

[24] Taha, Z., Rostam, S., 2012. A hybrid fuzzy AHP-PROMETHEE decision support system for machine tool selection in flexible manufacturing cell. Journal of Intelligent Manufacturing. 23(6), 2137-2149.

[25] Thürer, M., Tomašević, I., Stevenson, M., Qu, T., Huisingh, D., 2018. A systematic review of the literature on integrating sustainability into engineering curricula. Journal of Cleaner Production, 181, 608-617.

[26] Vargas, V.R., Lawthom, R., Prowse, A., Randles, S., Tzoulas, K., 2019. Implications of vertical policy integration for sustainable development implementation in higher education institutions. Journal of Cleaner Production, 235, 733740 .

[27] Wu, Y.C.J., Shen, J.P., 2016. Higher education for sustainable development: a systematic review. International Journal of Sustainability in Higher Education, 17(5), 633-651.

[28] Zhou, L., Rudhumbu, N., Shumba, J., Olumide, A., Nhamo, G., Mjimba, V., 2020. Role of Higher Education Institutions in the Implementation of Sustainable Development Goals, in: Nhamo, G., Mjimba, V. (Eds.), Sustainable Development Goals and Institutions of Higher Education. Springer International Publishing, Switzerland, pp, 87-96.

[29] Yuan, X., Zuo, J., 2013. A critical assessment of the Higher Education for Sustainable Development from students' perspectives e a Chinese study. Journal of Cleaner Production, 48, 108-115. 